\title{
OLD LUXATIONS OF THE LOWER CERVICAL SPINE
}

\author{
R. Braakman, Rotterdam and P. J. Vinken, Amsterdam, The Netherlands
}

During the past few years we have seen a number of patients with unilateral or bilateral cervical luxation - that is, interlocking of articular processes (Braakman and Vinken 1967)in whom the diagnosis was not made until some considerable time after injury. The following questions arose concerning these late cases: 1) Why was the diagnosis delayed? 2) Did the initial failure to recognise luxation affect treatment or prognosis?

In an attempt to answer these questions we have studied the case histories of all patients with cervical interlocking seen in the past fifteen years in three Dutch neurosurgical clinics. The material comprises thirty-seven cases of unilateral and thirty-five of bilateral interlocking (Table I). The total of seventy-two cases included thirty-six in which the interlocking had been present for more than two weeks (Table II). This group was separately considered under the heading "old luxation." The interval of two weeks was chosen because the chances of successful simple reduction of the interlocking rapidly diminish after this period. Of these thirty-six patients twenty-five came under our care more than two weeks after injury. In the eleven remaining patients, seen immediately after injury, the luxation was still present after two weeks.

The causes of the situation described as " old luxation" are reviewed in Table III. The principal cause is non-recognition of the interlocking immediately after injury, in spite of radiographic examination (twenty-five of the thirty-six cases). Only four patients failed to seek medical advice; two patients received medical treatment but were not examined radiologically. The four patients in whom reduction was not attempted all had total transverse lesions. Table IV indicates the interval between injury and the diagnosis of interlocking. Table V summarises the neurological symptoms in these cases.

There are three reasons for failure to recognise interlocking in spite of radiological examination: 1) the radiographs may be of inadequate quality; 2) the radiographs may fail to show all the cervical vertebrae, so that lower cervical interlocking is missed;3) interlocking is sometimes not recognised, even when clearly shown by radiographs of good quality.

These three causes of error will be considered in detail. Radiographs of inadequate quality were responsible in two cases in which the radiographic examination was made during the weekend or at night by inexperienced staff. In six cases the diagnosis of interlocking was missed because the lateral projections did not show the lower cervical vertebrae, which were obscured by the shoulder. This difficulty is especially likely to prevail in the presence of a transverse cord lesion, because these patients often lie with hunched shoulders. The following case history illustrates this.

\section{CASE REPORT}

Case 1-A bricklayer aged thirty-five was admitted to hospital with a total transverse lesion of the cord at the seventh cervical level, sustained in a fall from a height. Antero-posterior and lateral radiographs of the cervical spine were taken. The lateral radiographs showed the cervical vertebrae down to and including the fifth which were normal. The antero-posterior radiograph showed an increase in the distance between the spinous processes of the sixth and seventh vertebrae, but this was ignored. After two weeks the patient was transferred to the neurosurgical clinic where the lateral radiograph was repeated with downward traction on the arms. The bilateral luxation between the sixth and seventh vertebrae (suspected from the antero-posterior films) was then visible.

The six patients in whom interlocking had been overlooked for this reason all had luxation between the sixth and seventh cervical vertebrae or between the seventh cervical and first thoracic vertebrae. 
TABLE I

Level of Affection in Seventy-two Cases of Interlocking of Cervical Vertebrae

\begin{tabular}{|l|c|c|c|c|c|c|c|}
\hline Level . & C.2-C.3 & C.3-C.4 & C.4-C.5 & C.5-C.6 & C.6-C.7 & C.7-D.1 & Total \\
\hline Unilateral & 1 & 3 & 11 & 9 & 10 & 3 & 37 \\
\hline Bilateral . & - & - & 9 & 9 & 14 & 3 & 35 \\
\hline Total & 1 & 3 & 20 & 18 & 24 & 6 & 72 \\
\hline
\end{tabular}

TABLE II

Cases in which Interlocking Persisted for More than Two Weeks

\begin{tabular}{|l|c|c|c|c|c|c|c|}
\hline Level & C.2-C.3 & C.3-C.4 & C.4-C.5 & C.5-C.6 & C.6-C.7 & C.7-D.1 & Total \\
\hline Unilateral & 1 & 1 & 5 & 7 & 5 & 2 & 21 \\
\hline Bilateral . & - & - & 3 & 4 & 5 & 3 & 15 \\
\hline Total & 1 & 1 & 8 & 11 & 10 & 5 & 36 \\
\hline
\end{tabular}

TABLE III

Causes of Delay in Diagnosis

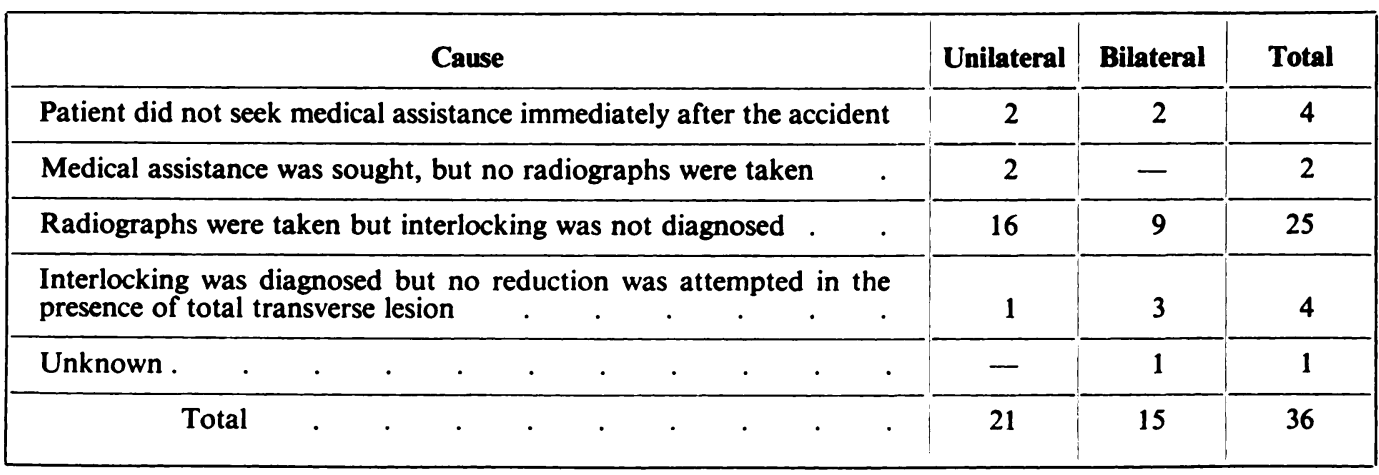

TABLE IV

Period between Injury and Diagnosis of Luxation

\begin{tabular}{|c|c|c|c|c|c|c|c|}
\hline & 2-4 weeks & 4-6 weeks & $6-8$ weeks & $\begin{array}{c}8 \text { weeks } \\
\text { to } \\
1 \text { year }\end{array}$ & $\begin{array}{c}\text { More } \\
\text { than } \\
1 \text { year }\end{array}$ & $\begin{array}{c}\text { Left } \\
\text { unreduced } \\
\text { on purpose }\end{array}$ & Total \\
\hline Unilateral & 5 & 3 & 2 & 7 & 3 & 1 & 21 \\
\hline Bilateral . & 3 & 2 & 1 & 4 & 2 & 3 & 15 \\
\hline
\end{tabular}

TABLE V

Neurological Symptoms in Old Luxations

\begin{tabular}{|l|c|c|c|c|c|c|}
\hline & $\begin{array}{c}\text { No } \\
\text { symptoms }\end{array}$ & $\begin{array}{c}\text { Root } \\
\text { lesion }\end{array}$ & $\begin{array}{c}\text { Reversible } \\
\text { cord } \\
\text { lesion }\end{array}$ & $\begin{array}{c}\text { Persistent } \\
\text { partial } \\
\text { cord lesion }\end{array}$ & $\begin{array}{c}\text { Persistent } \\
\text { transverse } \\
\text { lesion }\end{array}$ & $\begin{array}{c}\text { Progressive } \\
\text { cord } \\
\text { lesion }\end{array}$ \\
\hline Unilateral & 4 & $13^{*}$ & $4^{*}$ & 1 & - & - \\
\hline Bilateral . & 3 & 3 & 1 & 2 & 4 & 2 \\
\hline
\end{tabular}

* One particular patient had both a root lesion and cord lesion, and therefore appears under two different headings.

VOL. $50 \mathrm{~B}$, NO. 1, FEBRUARY 1968 
In twenty-five cases the readily visible displacement of the vertebral body was noticed and usually the diagnosis of "subluxation" was made, but the interlocking of the articular processes was overlooked. The following case report illustrates this.

CASE REPORT

Case 2-A woman aged twenty-seven sustained injuries in a motoring accident. "Subluxation" between the fifth and sixth vertebrae was diagnosed on the basis of relative displacement visible on radiographs. Interlocking of the articular processes was not identified until six weeks after admission. Review of the original radiographs showed that unilateral interlocking was clearly visible (Figs. 1 and 2).

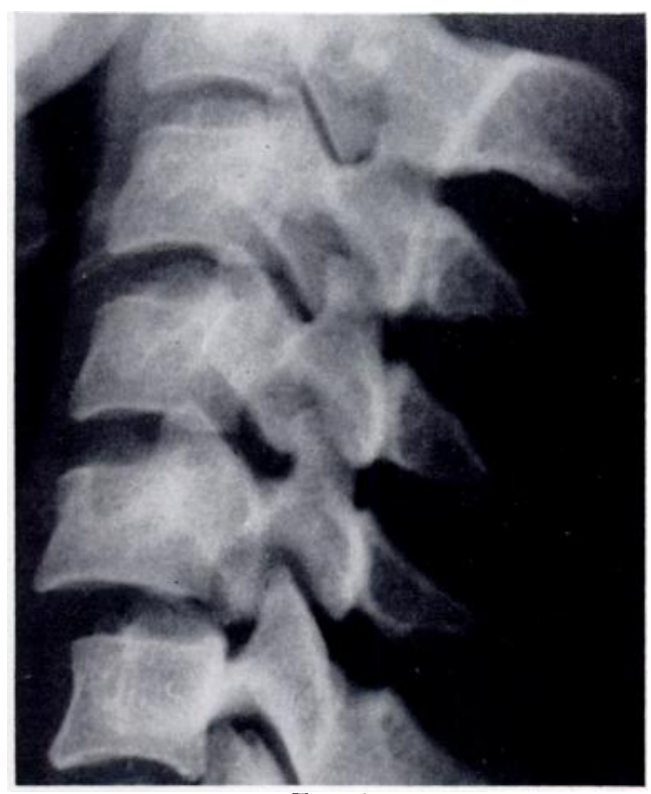

Fig. 1

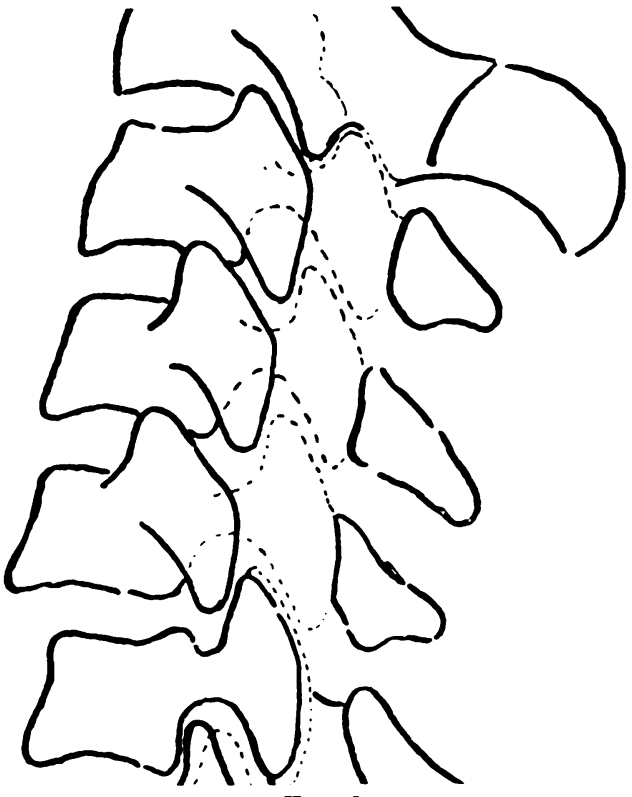

Fig. 2

Case 2. Figure 1-Lateral radiograph of cervical spine, showing unilateral interlocking between the fifth and sixth vertebrae. Figure 2-Schematic representation of the radiograph shown in Figure 1.

It seems therefore that the radiological features of unilateral and bilateral interlocking are insufficiently familiar to many radiologists and surgeons. This is probably because the average annual incidence of such interlocking is only one per million of the population.

\section{RADIOGRAPHIC TECHNIQUE}

The radiological examination of a patient with a suspected injury of the cervical spine must include: 1) an antero-posterior projection through the open mouth to show the relationship between atlas and axis; and 2) antero-posterior and lateral projections of the entire cervical spine which, if possible, should include the joint between the seventh cervical and first thoracic vertebrae. When the latter level is not shown clearly on the lateral radiograph, downward traction on the arms always succeeds in exposing the seventh vertebra, and sometimes also the articulation between it and the first thoracic vertebra. Stereoscopic views are always to be preferred to simple ones. All these radiographs can be made while the patient is still recumbent on the stretcher, with cranial traction or a stabilising collar; under these circumstances manipulation during the examination entails hardly any risk of aggravating the neurological damage.

If it is still impossible to demonstrate the joint between the seventh cervical and the first thoracic vertebrae, three-quarter views can be useful. For this purpose the patient is transferred 
to the $\mathrm{x}$-ray table and rotated through 55 degrees; if necessary, eccentric focusing from a cranial direction can be used (Ramadier and Bombart 1964) (Fig. 3).

Occasionally, lateral tomography is indicated; in three of our six patients with interlocking at the lowest level the dislocation could be seen only on tomographs. Tomography should
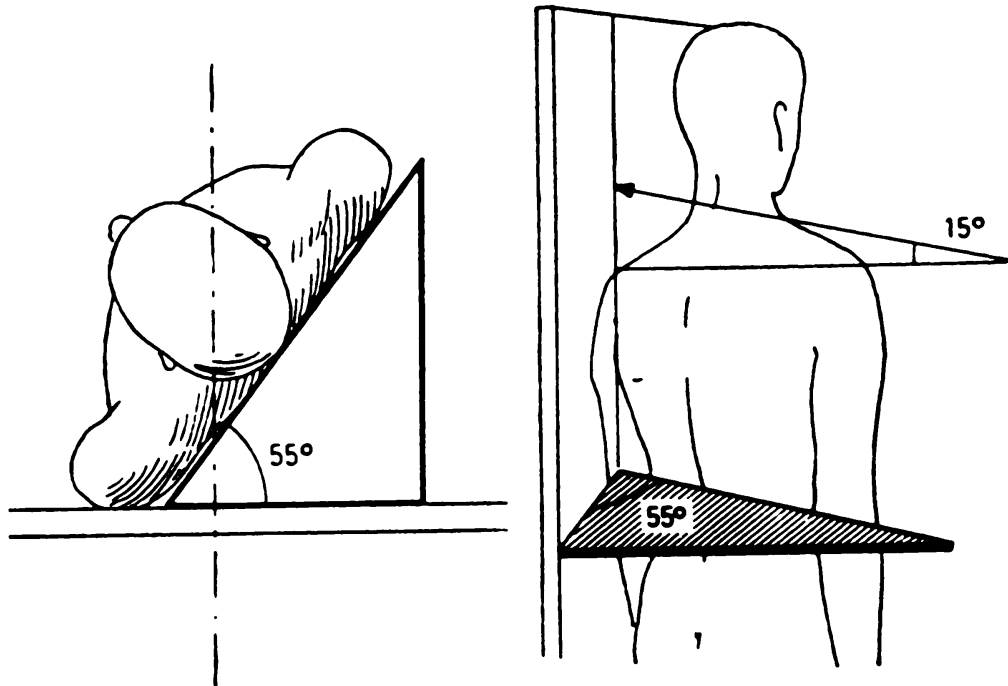

FIG. 3

Position with eccentric focusing from cranial direction to obtain three-quarter views (after Ramadier and Bombart (1964)).

be used only in patients with severe neurological damage which cannot adequately be explained on the basis of the pathogenic mechanisms and the radiological examination described above. Indications for this time-consuming examination should be carefully determined according to individual requirements because manipulations during tomography may cause exacerbation of the damage.

\section{RADIOLOGICAL DIAGNOSIS}

In bilateral luxation the bilateral interlocking shown on the lateral radiograph is characteristic (Fig. 4). The antero-posterior view usually discloses an increase of the distance between the spinous processes immediately above and below the dislocated segment (Fig. 5). This last characteristic, however, is absent in some cases (when the arch of the cranial luxated vertebra has broken off).

Unilateral luxation is characterised by a step in the line of the zygapophysial joints on one side, visible on the lateral radiograph (Figs. 1 and 2). In most cases stereoscopic radiographs are required to reveal the step. In the antero-posterior projection the spinous process is displaced towards the side of the luxation (Fig. 6), but this characteristic is often absent (when a hyperflexion injury of the interarticular joint on the contralateral side exists, without

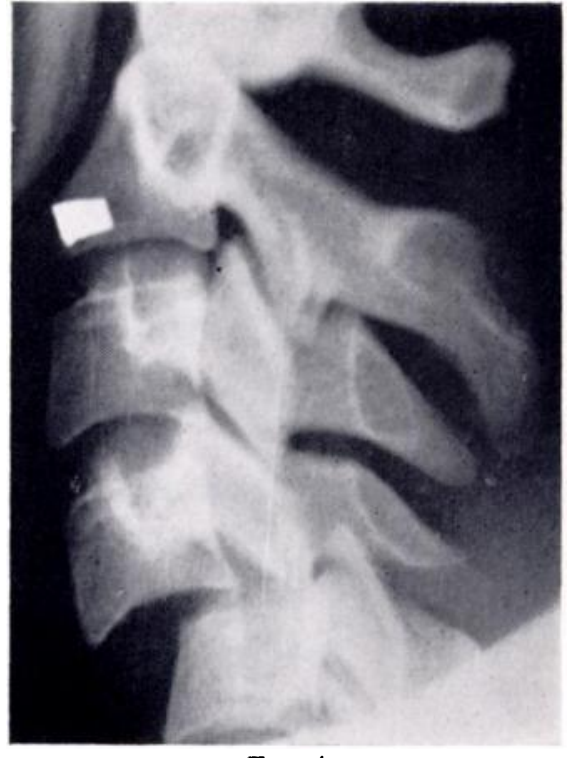

FIG. 4

Bilateral interlocking between the fourth and fifth cervical vertebrae. 
interlocking). In some cases, therefore, three-quarter projections or the projections described by Buetti-Bäuml (1954) may be useful. The essential point is to give special attention to the zygapophysial joints in all radiographs of patients with lesions of the cervical spine.

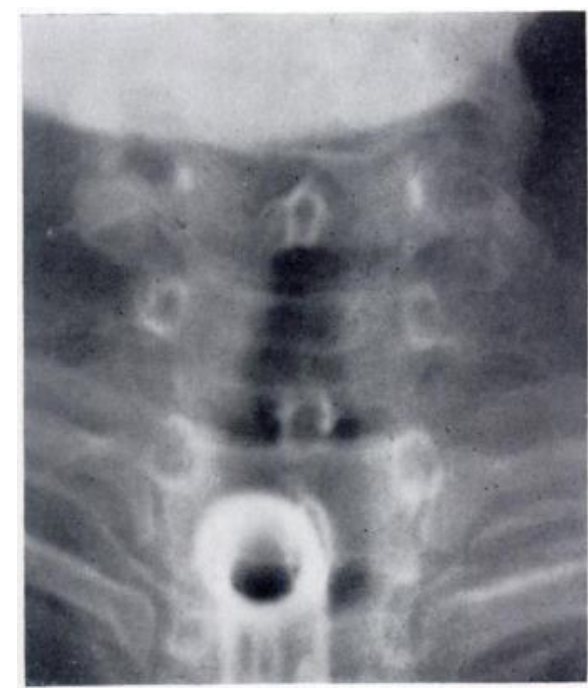

Fig. 5

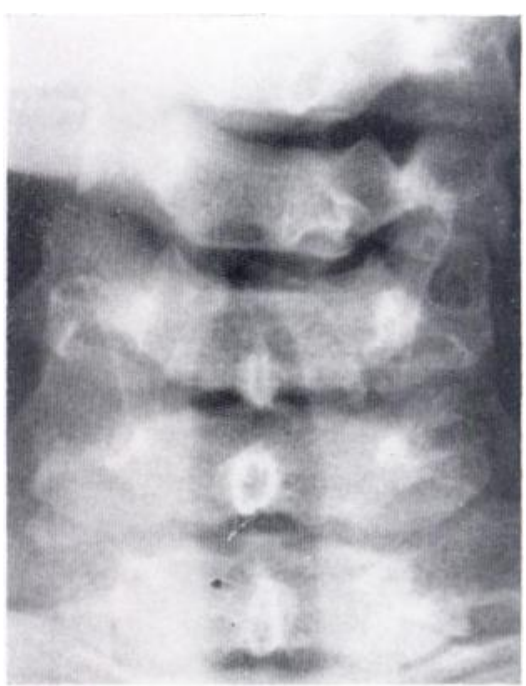

Fig. 6

Figure 5-Bilateral luxation between the sixth and seventh vertebrae. Antero-posterior view demonstrating increased distances between the spinous processes of the two vertebrae. Figure 6-Hemiluxation between fifth and sixth cervical vertebrae. Antero-posterior view, demonstrating the displacement of the spinous process to the side of the interlocking.

\section{NEUROLOGICAL ASPECTS OF TREATMENT}

Failure to diagnose interlocking promptly can affect the neurological prognosis unfavourably, for in recent interlocking early reduction is the best method of control of radicular symptoms (Braakman and Vinken 1967).

It might be expected also that in old interlocking recovery from neurological disorder would be promoted by reduction. In the present series, however, this was not demonstrable. Recovery from a radicular lesion occurred not only after successful reduction but also after failure of reduction (Table VI). On the other hand, successful reduction of an old luxation

TABLE VI

The Influence of Reduction on Neurological Symptoms

\begin{tabular}{|c|c|c|c|c|c|}
\hline & $\begin{array}{c}\text { No } \\
\text { neurological } \\
\text { symptoms }\end{array}$ & $\begin{array}{c}\text { Root } \\
\text { lesions }\end{array}$ & $\begin{array}{c}\text { Partial } \\
\text { cord } \\
\text { lesions }\end{array}$ & $\begin{array}{c}\text { Progressive } \\
\text { cord } \\
\text { lesions }\end{array}$ & Total \\
\hline Reduction successful & 3 & $\begin{array}{l}2 \text { cured } \\
1 \text { persisted }\end{array}$ & $\begin{array}{l}1 \text { cured } \\
1 \text { persisted }\end{array}$ & 1 cured & 9 \\
\hline Reduction failed & 1 & $\begin{array}{l}4 \text { cured } \\
1 \text { persisted }\end{array}$ & $\begin{array}{l}1 \text { cured } \\
1 \text { persisted }\end{array}$ & - & 8 \\
\hline
\end{tabular}

was not always followed by recovery from a radicular lesion. In the few cases with cord lesions, the course seemed to be determined less by the success or failure of reduction than by the type of cord lesion. The duration of the interval between luxation and reduction did not influence the neurological course. In our small series of nine patients with old luxations 
in whom reduction was successful, there was no distinct difference between those in whom reduction had been achieved within four weeks and in those in whom it was delayed longer.

Interesting exceptions were two patients who developed a progressive cord lesion some time after luxation, having shown initially no neurological abnormalities.

\section{CASE REPORTS}

Case 3-A racing-driver aged forty-two was admitted to hospital elsewhere, after a crash, with intense tingling sensations in the fingers of both hands. There was no neurological defect. The lateral radiographs of the cervical spine did not extend below the fifth cervical level, the sixth being obscured by the shoulder. The antero-posterior projection showed marked separation of the spinous processes of the sixth and seventh cervical vertebrae. The latter sign was ignored and the report stated "no abnormalities of the cervical spine." The patient was free from symptoms when discharged two weeks later. One week after discharge he developed pain in the neck and subsequently micturition was impaired. Progressive weakness of the limbs then developed. New radiographs disclosed interlocking of the sixth and seventh vertebrae. Operative reduction was followed by stabilisation of the cervical spine by posterior fusion; complete resolution of neurological symptoms followed.

Case 4-A nurse aged forty-nine fell on her head from a window. She complained of nuchal pain; an orthopaedic surgeon made a radiological examination and applied a plaster collar. Three years later pain in the legs developed and was followed within six months by a progressive cord syndrome with spastic paresis of the legs, disturbed sensation and mild impairment of micturition. After treatment elsewhere with a Glisson sling for three months the patient was admitted to our clinic. Radiographs disclosed bilateral interlocking of the seventh cervical and first thoracic vertebrae, with ligamentous ossification at this level and the level above and a pronounced low cervical flexion deformity. Lumbar puncture revealed a total block on the Queckenstedt test. Laminectomy of the seventh cervical and first thoracic vertebrae was rapidly followed by disappearance of the subjective and objective changes. The Queckenstedt test was normal after operation. A year later the patient was free from symptoms but there was a distinctly abnormal resting posture of the cervical spine, which caused no complaint.

These are exceptional cases and no reliable conclusion can be based on them. They merely show that patients with luxation can develop neurological symptoms even after a considerable time, but we have never observed this phenomenon after reduction of a luxation.

Summarising, we find that the effect of reduction on neurological symptoms in luxations of more than two weeks' duration is uncertain, but it does reduce the risk of late progressive cord symptoms.

\section{ORTHOPAEDIC ASPECTS OF TREATMENT}

Once the decision in favour of active treatment has been made, the following problems arise. How long after injury is reduction still feasible? Which technique of reduction should be used for old luxations? Is fixation after reduction desirable? Do attempts at reduction and fixation entail risks?

The literature gives little information about these questions because only sporadic or small numbers of cases have been reported. Crooks and Birkett (1944) successfully reduced after eleven days a luxation between the fifth and sixth cervical vertebrae in a patient who, during the second world war, travelled through France to England with this luxation and associated radicular symptoms. Watson-Jones (1955), Funke (1958), Ramadier and Bombart (1964) described a few cases of successful manipulative or non-manipulative reduction carried out one to three months after the injury. Verbiest (1962) described a case in which he made an anterior approach to the cervical spine. He contends that, in this approach, removal of the anterior longitudinal ligament and excision of the intervertebral disc eliminates structures which, through cicatrization, prevent reduction. In this manner, he claims, he reduced luxation after eight months. On the other hand, in two of Ramadier and Bombart's patients late reduction caused aggravation of cord symptoms; consequently they leave alone any luxation more than a month old, resorting to operative fixation of the cervical spine in the position of luxation.

VOL. $50 \mathrm{~B}$, NO. 1, FEBRUARY 1968 
In our own cases no rigid policy was followed. Consequently our experience with each of the various procedures is relatively limited, but the series of cases described in this paper is nevertheless the largest so far reported. The general plan of treatment is shown in Figure 7.

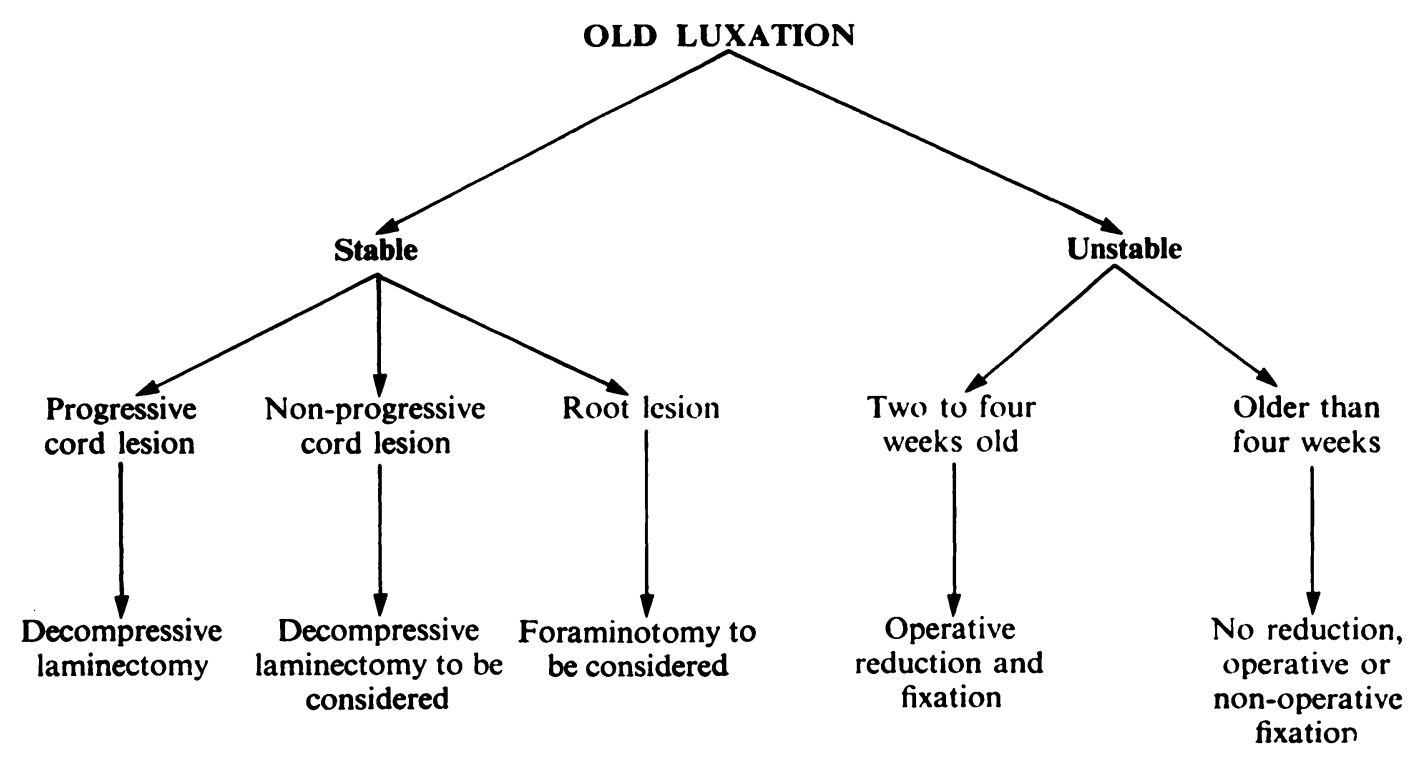

Fig. 7

The general plan of treatment of unreduced luxations.

Reduction-Table VII indicates the results of various techniques of reduction used in our series. These results warrant the following conclusions: 1) Traction without anaesthesia, using a Glisson sling, or caliper traction with small weights, is bound to fail. 2) Operative reduction has the best chance of success. 3) Both manual traction under anaesthesia with muscle relaxation, and protracted caliper traction with large weights (over 10 kilograms) without anaesthesia, are sometimes successful. 4) Although reduction may occasionally be achieved even after months it is nevertheless contra-indicated after an interval of more than six weeks, because the chance of success is poor and because the attempt may aggravate the

TABLE VII

Results of Various TechniQues of Reduction

\begin{tabular}{|c|c|c|c|c|c|c|}
\hline $\begin{array}{l}\text { Duration of } \\
\text { luxation }\end{array}$ & $\begin{array}{l}\text { No } \\
\text { reduction }\end{array}$ & $\begin{array}{c}\text { Caliper } \\
\text { traction } \\
\text { less than } \\
10 \text { kilograms }\end{array}$ & $\begin{array}{c}\text { Caliper } \\
\text { traction } \\
\text { more than } \\
10 \text { kilograms }\end{array}$ & $\begin{array}{c}\text { Manual } \\
\text { reduction } \\
\text { under general } \\
\text { anaesthesia }\end{array}$ & $\begin{array}{l}\text { Operative } \\
\text { reduction }\end{array}$ & $\begin{array}{c}\text { Total } \\
\text { number of } \\
\text { cases }\end{array}$ \\
\hline 2-4 weeks. & - & $\begin{array}{l}0 \text { succeeded } \\
2 \text { failed }\end{array}$ & 1 succeeded & $\begin{array}{l}2 \text { succeeded } \\
2 \text { failed }\end{array}$ & $\begin{array}{l}1 \text { succeeded } \\
1 \text { failed }\end{array}$ & 8 \\
\hline 4-6 weeks. & 1 & 1 failed & 1 succeeded & 1 failed & $\begin{array}{l}1 \text { succeeded } \\
1 \text { failed }\end{array}$ & 5 \\
\hline 6-8 weeks. & 1 & - & - & 2 failed & 2 succeeded & 3 \\
\hline 8 weeks to 1 year & 8 & - & 一 & 1 failed & $\begin{array}{l}1 \text { succeeded } \\
1 \text { failed }\end{array}$ & 11 \\
\hline More than 1 year & 5 & - & - & - & - & 5 \\
\hline
\end{tabular}

Note: The number of cases is not always the same as the number of attempts at reduction because in some patients reduction was attempted in several ways. 
neurological symptoms. The complications descrited by Ramadier and Bombart (1964) demand consideration in this connection. In these cases the interlocking is best left alone. Stability-Further treatment depends on the nature of the lesion (luxation reduced or still present) and its stability. The lesion is unstable: 1) immediately after successful reduction; 2 ) if in spite of unsuccessful reduction a change in position occurs during traction (for instance, widening of the disc space); and 3) if radiographs made at intervals of a few weeks show that the vertebral column is undergoing progressive deformity whether or not the luxation has been reduced.

The presence of ossification in the ruptured posterior ligaments, or beneath the anterior longitudinal ligament, is no guarantee of stability but it does indicate that the injured segment is undergoing stabilisation. Luxations more than four months old are nearly always stable. Fixation-If it can be concluded from the above criteria that there is no stability, fixation is indicated. The choice between operative and non-operative fixation must be made in each case, and in this respect it should be remembered that stability almost always occurs eventually, regardless of treatment and the severity of the lesion. The following case is an example.

\section{CASE REPORT}

Case 5-A man aged sixty-seven fell down a staircase and did not report for treatment until two months later, when nuchal pain and tingling in the hands had developed. Radiographs disclosed interlocking of the fourth and fifth cervical vertebrae, with distinct forward displacement of the fourth relative to the fifth. Films taken in flexion and extension indicated stability of the affected segment, and, partly because of his age, the patient was merely given a small plaster collar. Ossification gradually occurred in front of the intervertebral disc and the symptoms disappeared. Deformity of the vertebral column did not increase, and radiographs in flexion and extension repeated six months later showed that the affected segment was completely immobile. Figure 8 shows the condition two years after injury.

The method of fixation is determined by a number of factors. 1) Neurological features: in the presence of a transverse lesion external fixation by plaster is contra-indicated; prolonged bed rest, as on a turning frame, with or without traction, or internal fixation are the only remaining possibilities. 2) The severity of the lesion: severe lesions such as bilateral luxation, or hemiluxation with fracture of the contralateral articular process, or with a compression fracture of an adjacent vertebra, are better treated by operative fixation than is, say, simple hemiluxation. 3) The method of reduction: whenever reduction is done by operation, internal fixation is the obvious choice. 4) Secondary factors, such as age and general health.

If a patient is mobilised within a few weeks of operative fixation the application of a plaster jacket is advisable. In reduction and fixation it is unnecessary to secure anatomical perfectionfor example, to perform a vertebral osteotomy

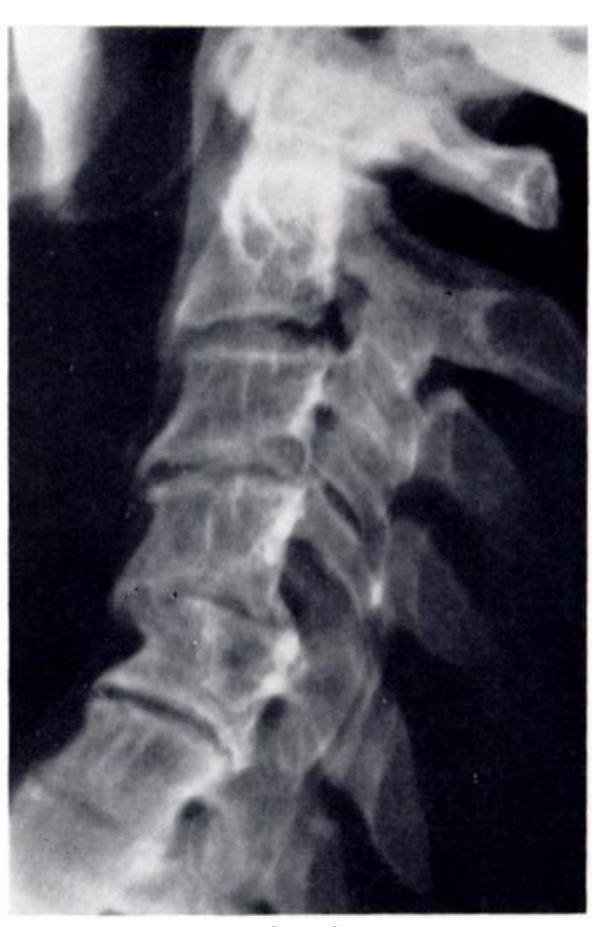

FIG. 8

Case 5-Interlocking between fourth and fifth cervical vertebrae. Lateral view, taken two years after injury.

for restoration of the spinal column to its normal shape. An abnormal position does not, in our experience, give rise to symptoms if fixation is adequate.

In the presence of adequate stability there are four possibilities, as follows. 1) Symptoms and neurological changes are absent, when no treatment is required. 2) Persistent or progressive 
symptoms of root compression call for decompression by foraminotomy, if necessary with renewed operative fixation. We have no personal experience of this procedure because our only patient in this group refused operation. 3) In the presence of a static neurological syndrome the nature of the syndrome and the findings at lumbar puncture determine whether decompression by laminectomy is indicated. In general, laminectomy should be considered only in cases of anterior cord syndrome or subtotal transverse lesion, especially in the presence of a manometric block (Braakman and van der Werf 1962). 4) In exceptional cases established stability may be accompanied by a progressive cord syndrome which calls for laminectomy. This is illustrated by the events in our quite exceptional Case 4 .

\section{SUMMARY}

1. In thirty-six out of seventy-two cases of cervical vertebral interlocking, luxation was still present after two weeks (“old luxation"). The principal reasons for overlooking the diagnosis are lack of familiarity with the radiographic appearances and incomplete or inadequate radiographic examination.

2. Failure to identify luxation probably hardly influences the prognosis of the immediate cord lesion; but recovery from the radicular lesion is unfavourably affected, and a progressive cord lesion may occur later when none previously existed.

3. Reduction is advisable if the luxation is not more than six weeks old. Operative reduction is preferred; manual reduction under anaesthesia and caliper traction with heavy weights are less satisfactory alternatives. Reduction is contra-indicated if the luxation is more than six weeks old.

4. Indications for fixation and the choice between internal and external (plaster jacket) fixation are discussed, and also the treatment of stable lesions which have not been reduced.

\section{REFERENCES}

BraAkman, R., and van der Werf, A. J. M. (1962): L'indication opératoire dans les traumatismes cervicaux. Neuro-Chirurgie, 8, 263.

BraAkman, R., and Vinken, P. J. (1967): Unilateral Facet Interlocking in the Lower Cervical Spine. Journal of Bone and Joint Surgery, 49-B, 249.

Buetti-BäUmL, C. (1954): Funktionelle Röntgendiagnostik der Halswirbelsäule. Stuttgart: Georg Thieme Verlag. Crooks, R., and Birketr, A. N. (1944): Fractures and Dislocations of the Cervical Spine. British Journal of Surgery, 31, 252.

FUNKE, H. (1958): Unblutige Reposition einer vollständigen Halswirbelkörperverrenkung. Zentralblatt für Chirurgie, 83, 1668.

Ramadier, J. O., and BombarT, M. (1964): Fractures et luxations du rachis cervical sans lésions médullaires, 2e partie. Lésions des 5 dernières vertèbres cervicales. Revue de chirurgie orthopédique et réparatrice de l'appareil moteur, 50, 3.

Verbiest, H. (1962): Anterior Operative Approach in Cases of Spinal-cord Compression by Old Irreducible Displacement or Fresh Fracture of Cervical Spine. Journal of Neurosurgery, 19, 389.

Watson-Jones, R. (1955): Fractures and Joint Injuries. Fourth edition. Volume 2. Edinburgh and London: E. \& S. Livingstone Ltd. 